
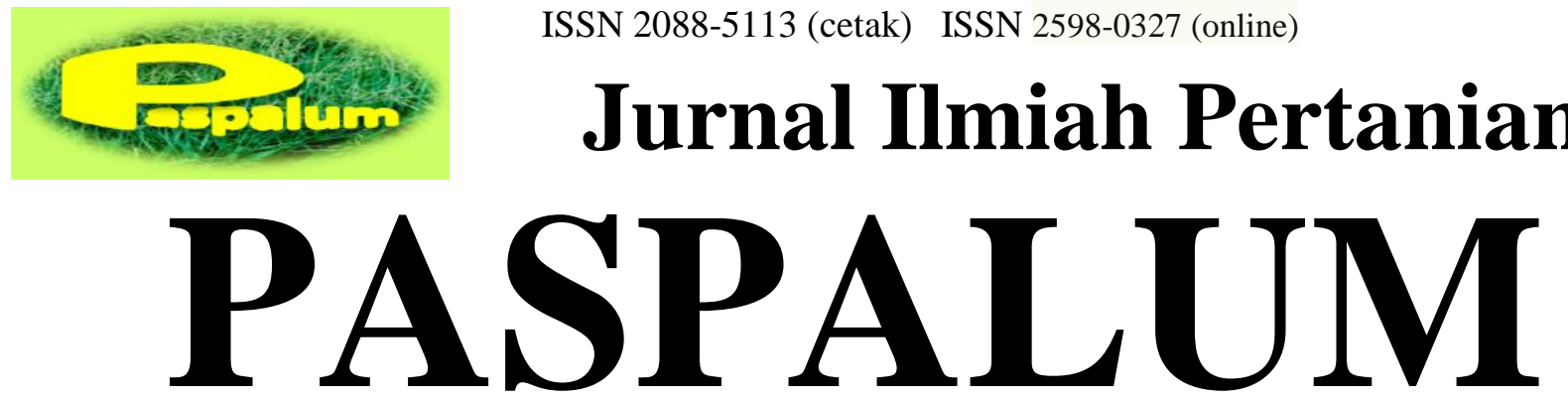

Volume. 6 No. 1 Bulan Maret Tahun 2018

http://journal.unwim.ac.id/index.php/paspalum

\title{
Identifikasi Mutu Fisik Dan Fisiologis 16 Genotip Benih Calon Tetua Jagung Manis Hibrida Unpad setelah 2 dan 4 Bulan Penyimpanan
}

\author{
Debby Yolanda Sulista, Anne Nuraini, Muhamad Kadapi. \\ Agroteknologi, Agronomy, Universitas Padjadjaran \\ debbyyolandasulista@gmail.com
}

Diterima tgl : 10-02-2018 dan disetujui untuk diterbitkan tgl : 31-03-2018

\begin{abstract}
Hybrid seed is not always have good longetivity. Therefore, breeder should select longetivity character from parental lines to get hybrid with longetivity characeter. Longetivity character can be revealed by physical and physiological identification of seed. The aim of this research was to identify physical and physiological of 16 parental lines genotypes of sweetcorn after storage. The experimental design in this research used Randomized Complete Design. The treatment in this reserach used 16 Unpad sweet corn parental lines with two replications. The data were analyzed using the F test, Scott Knott 5\%, and Duncan 5\%. The results showed that there were significant differences in seed electrical conductivity, germination capacity, vigor index, normal seedling dry weight and 100 seeds weight, and seed growth simultaneously at 2 month storage, and normal seedling dry weight and 100 seeds weight at 4 month storage. The best genotypes after storage was 578 which was from $P$ parent, according to the delta value of seed quality changed.
\end{abstract}

Keywords: Genotypes, hybrid sweet corn, storage, parental line,physical quality, physiological quality.

\begin{abstract}
Abstrak
\section{PENDAHULUAN}

Jagung manis merupakan jenis jagung yang digemari penduduk Indonesia (Purwono, 2008). Permintaan akan jagung manis terus meningkat namun dalam pemenuhannya mengalami ketimpangan (Badan Pusat Statistik, 2016).
\end{abstract}

Dalam memproduksi benih jagung manis hibrida yang tahan simpan, diperlukan tetua yang memiliki karakter tahan simpan. Karakter tahan simpan benih dapat diperoleh dengan identifikasi mutu fisik dan fisiologis. Tujuan penelitian ini untuk mendapatkan genotip benih calon tetua jagung manis hibrida dari 16 genotip yang memiliki mutu fisik dan fisiologis terbaik setelah 2 dan 4 bulan penyimpanan. Penelitian menggunakan Rancangan Acak Lengkap dengan 16 perlakuan genotip jagung manis dengan dua ulangan. Data dianalisis dengan uji $F$, jika berbeda nyata diuji lanjut dengan uji Scott Knott taraf 5\% dan duncan taraf 5\%. Hasil penelitian menunjukkan bahwa terdapat perbedaan nyata pada parameter daya hantar listrik, daya berkecambah, indeks vigor, bobot kering kecambah normal, bobot 100 butir ,dan keserempakan tumbuh pada 2 BSP, bobot kering kecambah normal, dan bobot 100 butir pada 4 BSP. Genotip terbaik setelah penyimpanan 2 dan 4 bulan adalah Genotip 578 yang berasal dari galur $P$ berdasarkan data perubahan genotip yang terbaik.

Kata kunci: Calon tetua, genotip, jagung manis hibrida, mutu fisik dan mutu fisiologis,penyimpanan.

Upaya untuk menyokong pemenuhan permintaan jagung manis dapat dilakukan dengan penggunaan varietas unggul bermutu (Direktorat Jenderal Tanaman Pangan, 2017). Pemerintah dalam menyikapi permasalahn pemenuhan permintaan jagung melakukan "Gerakan Pengembangan Jagung Hibrida" 
(Direktorat Jenderal Tanaman Pangan, 2016). Potensi produktivitas jagung hibrida mencapai 10-13 ton ha ${ }^{-1}$ (Azizah dkk., 2017). Pemakaian benih bermutu untuk varietas unggul harus disokong dengan baik penyediaannya. Pentingnya ketersediaan benih harus memenuhi syarat baik kualitas, kuantitas, dan kontinyuitas (Direktorat Jenderal Tanaman Pangan, 2016).

Menghasilkan jagung manis hibrida yang unggul bermutu dirakit dimulai dengan membentuk galur atau lini inbredsabagai calon tetua. Inbred dapat dibentuk menggunakan bahan bersari bebas.Pembentukan inbred pada dasarnya melalui seleksi tanaman dan tongkol selamasilang sendiri (Takdir dkk., 1987). Perakitan varietas hibrida unggul dilakukan denganmenggunakan tetua yang dihasilkan dari berbagai pengujian dengan tujuan mendapatkan sifat yang diinginkan (Kusandriani \& Permadi, 1996).

Benih hibrida tidak dapat ditanam kembali menjadi sumber benih sehingga benih harus memiliki karakter tahan simpan agar dapat ditanam pada musim tanam berikutnya dengan laju deteriorasi rendah (Badan Penelitian dan Pengembangan Pertanian, 2008). Karakter tahan simpan dapat didapat melalui identifikasi mutu fisik dan fisiologis (Azizah dkk., 2017). Hasil dari identifikasi mutu fisik dan fisiologis diseleksi dan dimungkinkan dapat dijadikan calon tetua dengan karakter tahan simpan untuk menghasilkan benih jagung manis hibrida yang tahan simpan.

Tujuan penelitian ini untuk mendapatkan genotip benih calon tetua jagung manis hibrida dari ke 16 yang memiliki periode simpan paling tinggi oleh mutu fisik dan fisiologis terbaik. Hasil penelitian ini diharapkan dapat menambah informasi tentang genotip calon tetua jagung manis hibrida terindentifikasi yang memiliki daya simpan paling tinggi sebagai calon tetua jagunga manis bermutu dari genotip yang paling unggul yang sudah dihasilkan.

\section{METODE}

Percobaan dilakukan di Laboatorium Pemuliaan Tanaman dan Teknologi Benih Departemen Budidaya Pertanian Fakultas Pertanian Universitas Padjadjaran pada bulan Juli hingga bulan November 2017. Suhu dan kelembaban harian selama penyimpanan adalah $25,31^{\circ} \mathrm{C}$ dan $61,81 \%$ yang mengalami fluktuasi pada buan pertama sampai akhir penyimpanan (Tabel 1). Bahan yang digunakan adalah 16 genotip calon tetua jagung manis hibrida (Tabel 2). 16 genotip calon tetua jagung manis sebagai perlakuan dengan dua ulangan yang merupakan genotip yang berasal dari hasil persilangan dari populasi $\mathrm{P}$ dan galur SR yang disilangkan dengan varietas komersil (Latanza, Sweet Boy, Jambore, Bonanza).

Percobaan menggunakan metode eksperimental dengan Rancangan Acak Lengkapp (RAL) (Gasperz, 1995). Data hasil pengamatan dianalisis secara statistik dengan uji $\mathrm{F}$ (anova), dan diuji lanjut untuk mendapat genotip terbaik menggunakan uji Scott Knott taraf 5\% dan uji Duncan taraf 5\%. Karakter yang diamati yaitu kadar air, bobot 100 butir, daya hantar listrik, dan daya berkecambah.

Tabel 1. Rata-rata suhu dan kelembaban (RH) selama penyimpanan $2 \& 4$ BSP

\begin{tabular}{ccc}
\hline \multirow{2}{*}{$\begin{array}{c}\text { Bulan } \\
\text { ke- }\end{array}$} & \multicolumn{2}{c}{ Pengamatan } \\
\cline { 2 - 3 } & $\begin{array}{c}\text { Rata-rata } \\
\text { suhu/bln }\end{array}$ & $\begin{array}{c}\text { Rata-rata } \\
\text { RH/bln }\end{array}$ \\
\hline 1 & 25,18 & 62,96 \\
2 & 25,51 & 58,51 \\
3 & 25,61 & 59,71 \\
4 & 24,89 & 63,91 \\
Rata- & $\mathbf{2 5 , 3 1}$ & $\mathbf{6 1 , 8 1}$ \\
rata & & \\
\hline
\end{tabular}

\section{HASIL DAN PEMBAHASAN}

\section{Kadar Air}

Kerusakan benih selama penyimpanan sebagian besar dipengaruhi oleh kadar airbenih (Justice dan Bass, 2002). Berdasarkan data analisis statistik kadar air penyimpanan 16 
55 I Paspalum: Jurnal IImiah Pertanian Vol.6, No.1, Maret 2018

genotip jagung manis pada penyimpanan $2 \& 4$ BSP tidak berbeda nyata namun cenderung meningkat dari 2 ke 4 BSP.

Hasil pengamatan menyatakan bahwa kadar air pada penyimpanan dari 0 BSP sampai 4 BSP mengalami fluktuasi, dari 0 ke 2 BSP rata-rata menurun, dan dari 2 ke 4 BSP ratarata meningkat (Tabel 3). Fluktuasi kadar air diduga disebabkan oleh fluktuasi kelembaban selama penyimpanan (Tabel 1).

Tabel 2. Perlakuan Calon Tetua Benih Jagung Manis

\begin{tabular}{cccc}
\hline No & Genotip & No & Genotip \\
\hline 1 & 547 & 9 & 848 \\
2 & 578 & 10 & 844 \\
3 & 628 & 11 & 857 \\
4 & 666 & 12 & 824 \\
5 & 664 & 13 & 849 \\
6 & 699 & 14 & 835 \\
7 & 711 & 15 & 837 \\
8 & 722 & 16 & 858 \\
\hline Ket: Genotip nomor 1-8 & adalah galur \\
populasi P, dan Genotip nomor 9-16 \\
adalah galur populasi SR.
\end{tabular}

\section{Daya Hantar Listrik}

Nilai daya hantar listrik menjadi tolok ukur dari vigor suatu benih yang merupakan pengujian secara tidak langsung pada benih (Sadjad, 1993). Berdasarkan data analisis statistik daya hantar listrik 16 genotip jagung manis berbeda nyata pada 2 BSP \& tidak berbeda nyata pada 4 BSP. Genotip dengan saya hantar listrik terbaik adalah genotip 835 .

Nilai DHL pada seluruh genotip meningkat seiring dengan peningkatan kadar air yang dapat dilihat padaTabel 3 sampai akhir periode simpan. Kadar air benih yang tinggi berakibat pada peningkatan permeabilitas membran (Tatipata dkk, 2004).
Tabel 3. Pengaruh Genotip terhadap Kadar Air 16 Genotip Calon Tetua Jagung Manis Hibrida Unpad

\begin{tabular}{|c|c|c|c|c|}
\hline \multirow{3}{*}{$\begin{array}{l}\text { Gen } \\
\text { otip }\end{array}$} & \multicolumn{4}{|c|}{ Kadar Air (\%) } \\
\hline & \multirow{2}{*}{$\begin{array}{c}2 \\
\text { BSP }\end{array}$} & \multirow{2}{*}{4 BSP } & \multicolumn{2}{|c|}{$\begin{array}{c}\text { Rata-rata } \\
\text { perubahan }\end{array}$} \\
\hline & & & $\begin{array}{l}0-2 \\
\text { BSP }\end{array}$ & $\begin{array}{l}2-4 \\
\text { BSP }\end{array}$ \\
\hline 547 & $11,1 \mathrm{a}$ & $13,6 \mathrm{a}$ & $-3,293$ & 2,370 \\
\hline 578 & $11,2 \mathrm{a}$ & $13,1 \mathrm{a}$ & $-3,525$ & 1,891 \\
\hline 628 & $11,5 \mathrm{a}$ & $13,3 \mathrm{a}$ & $-3,278$ & 1,863 \\
\hline 666 & $11,4 \mathrm{a}$ & $12,9 \mathrm{a}$ & $-3,759$ & 1,506 \\
\hline 664 & $11,3 \mathrm{a}$ & $13,3 \mathrm{a}$ & $-3,323$ & 2,002 \\
\hline 699 & $11,4 \mathrm{a}$ & $13,2 \mathrm{a}$ & $-3,688$ & 1,745 \\
\hline 711 & $11,2 \mathrm{a}$ & $13,8 \mathrm{a}$ & $-2,932$ & 2,552 \\
\hline 722 & $11,1 \mathrm{a}$ & $13,1 \mathrm{a}$ & $-3,514$ & 1,969 \\
\hline 848 & $11,4 \mathrm{a}$ & $13,6 \mathrm{a}$ & $-3,38$ & 2,211 \\
\hline 844 & $9,6 \mathrm{a}$ & $12,4 \mathrm{a}$ & $-4,430$ & 2,816 \\
\hline 857 & $11,3 \mathrm{a}$ & $13,4 \mathrm{a}$ & $-2,701$ & 2,176 \\
\hline 824 & $11,2 \mathrm{a}$ & $13,4 \mathrm{a}$ & $-2,963$ & 2,229 \\
\hline 849 & $11,9 \mathrm{a}$ & $14,3 \mathrm{a}$ & $-1,759$ & 2,328 \\
\hline 835 & $11,2 \mathrm{a}$ & $13,6 \mathrm{a}$ & $-3,380$ & 2,416 \\
\hline 837 & $12,4 \mathrm{a}$ & $13,9 \mathrm{a}$ & $-1,672$ & 1,436 \\
\hline 858 & $10,9 \mathrm{a}$ & $13,3 \mathrm{a}$ & $-3,112$ & 2,386 \\
\hline
\end{tabular}

\section{Bobot 100 butir}

Berdasarkan data analisis statistik bobot 100 butir menunjukan 16 genotip jagung manis berbeda nyata baik pada $2 \& 4$ BSP (Tabel. 5). Bobot 100 butir benih yang tertinggi adalah genotip 664 dan 699.

Penurunan bobot 100 butir pada 0-2 BSP secara serempak diduga karena penurunan kadar air benih yang juga serempak. Pada 2-4 BSP penurunan bobot 100 butir yang paling kecil adalah genotip 849, sedangkan penurunan paling besar adalah genotip 848 pada Penurunan bobot pada 2-4 BSP diduga karena serangan kutu jagung yang cukup besar. 
56 I Paspalum: Jurnal IImiah Pertanian Vol.6, No.1, Maret 2018

Tabel 4. Pengaruh Genotip terhadap Daya Hantar Listrik 16 Genotip Calon Tetua Jagung Manis Hibrida Unpad

\begin{tabular}{|c|c|c|c|c|}
\hline \multirow{3}{*}{$\begin{array}{l}\text { Gen } \\
\text { otip }\end{array}$} & \multicolumn{4}{|c|}{ Daya Hantar Listrik $(\mu S / g)$} \\
\hline & \multirow[b]{2}{*}{2 BSP } & \multirow[b]{2}{*}{4 BSP } & \multicolumn{2}{|c|}{ Rata-rata kenaikan } \\
\hline & & & $0-2 \mathrm{BSP}$ & $\begin{array}{l}2-4 \\
\text { BSP }\end{array}$ \\
\hline 547 & $0,04 \mathrm{a}$ & $0,08 \mathrm{a}$ & $0,02 \mathrm{bcd}$ & $0,04 \mathrm{a}$ \\
\hline 578 & $0,04 \mathrm{a}$ & $0,09 \mathrm{a}$ & $0,02 \mathrm{bcd}$ & $0,04 \mathrm{a}$ \\
\hline 628 & $0,04 \mathrm{a}$ & $0,05 \mathrm{a}$ & $0,02 \mathrm{bc}$ & $0,04 \mathrm{a}$ \\
\hline 666 & $0,05 \mathrm{a}$ & $0,06 \mathrm{a}$ & $0,02 \mathrm{bc}$ & $0,05 \mathrm{a}$ \\
\hline 664 & $0,05 \mathrm{a}$ & $0,08 \mathrm{a}$ & $0,03 \mathrm{ab}$ & $0,05 \mathrm{a}$ \\
\hline 699 & $0,04 \mathrm{a}$ & $0,06 \mathrm{a}$ & $0,02 \mathrm{bcd}$ & $0,04 \mathrm{a}$ \\
\hline 711 & $0,04 \mathrm{a}$ & 0,09 a & $0,01 \mathrm{bcd}$ & $0,04 \mathrm{a}$ \\
\hline 722 & $0,04 \mathrm{a}$ & $0,05 \mathrm{a}$ & $0,02 \mathrm{bcd}$ & $0,04 \mathrm{a}$ \\
\hline 848 & $0,04 \mathrm{a}$ & $0,09 \mathrm{a}$ & $0,02 \mathrm{bc}$ & $0,04 \mathrm{a}$ \\
\hline 844 & $0,05 \mathrm{a}$ & $0,06 \mathrm{a}$ & $0,02 \mathrm{bcd}$ & $0,05 \mathrm{a}$ \\
\hline 857 & $0,04 \mathrm{a}$ & $0,06 \mathrm{a}$ & $0,01 \mathrm{bcd}$ & $0,04 \mathrm{a}$ \\
\hline 824 & $0,03 \mathrm{a}$ & $0,08 \mathrm{a}$ & $0,01 \mathrm{bcd}$ & $0,03 \mathrm{a}$ \\
\hline 849 & $0,02 \mathrm{a}$ & $0,08 \mathrm{a}$ & $0,006 \mathrm{~cd}$ & $0,02 \mathrm{a}$ \\
\hline 835 & $0,04 \mathrm{a}$ & $0,04 \mathrm{a}$ & $0,0006 \mathrm{~d}$ & $0,04 \mathrm{a}$ \\
\hline 837 & $0,07 \mathrm{a}$ & $0,07 \mathrm{a}$ & $0,04 \mathrm{a}$ & $0,07 \mathrm{a}$ \\
\hline 858 & $0,04 \mathrm{a}$ & $0,06 \mathrm{a}$ & $0,01 \mathrm{bcd}$ & $0,04 \mathrm{a}$ \\
\hline
\end{tabular}

Tabel 5. Pengaruh Genotip terhadap Bobot 100 Butir 16 Genotip Calon Tetua Jagung Manis Hibrida Unpad

\begin{tabular}{ccccc}
\hline & \multicolumn{4}{c}{ Bobot 100 Butir (g) } \\
\cline { 2 - 5 } Gen & & & \multicolumn{3}{c}{ Rata-rata perubahan } \\
\cline { 3 - 5 } & 2 BSP & 4 BSP & $0-2$ & $2-4$ BSP \\
& & & BSP & \\
\hline 547 & $12,27 \mathrm{c}$ & $11,68 \mathrm{c}$ & $-0,21$ & $-0,6 \mathrm{cde}$ \\
578 & $12,10 \mathrm{c}$ & $12,41 \mathrm{~b}$ & $-0,77$ & $0,31 \mathrm{abc}$ \\
628 & $9,86 \mathrm{~g}$ & $10,28 \mathrm{~d}$ & $-0,4$ & $0,415 \mathrm{ab}$ \\
666 & $12,92 \mathrm{~b}$ & $12,92 \mathrm{~b}$ & $-1,04$ & 0 abcd \\
664 & $13,99 \mathrm{a}$ & $13,36 \mathrm{a}$ & $-1,11$ & $-0,635 \mathrm{de}$ \\
& & & & $-0,235$ \\
699 & $13,76 \mathrm{a}$ & $13,54 \mathrm{a}$ & $-0,34$ & $\mathrm{abcde}$ \\
711 & $12,11 \mathrm{c}$ & $11,64 \mathrm{c}$ & $-0,72$ & $-0,465 \mathrm{bcde}$ \\
722 & $13,22 \mathrm{~b}$ & $12,85 \mathrm{~b}$ & $-0,33$ & $-0,37 \mathrm{abcde}$ \\
848 & $10,60 \mathrm{e}$ & $11,20 \mathrm{c}$ & $-1,32$ & $0,6 \mathrm{a}$ \\
844 & $11,85 \mathrm{c}$ & $11,29 \mathrm{c}$ & $-0,02$ & $-0,565 \mathrm{bcde}$ \\
857 & $10,86 \mathrm{e}$ & $10,51 \mathrm{~d}$ & $-0,02$ & $-0,35$ abcde \\
\hline
\end{tabular}

Terusan Tabel 3.

\begin{tabular}{llllc}
\hline 849 & $9,65 \mathrm{~g}$ & $8,63 \mathrm{e}$ & $-0,52$ & $-1,025 \mathrm{e}$ \\
835 & $9,35 \mathrm{~h}$ & $9,16 \mathrm{e}$ & $-0,17$ & $-0,22$ abcde \\
837 & $9,27 \mathrm{~h}$ & $9,07 \mathrm{e}$ & 0,655 & $-0,2$ abcde \\
858 & $10,23 \mathrm{f}$ & $9,45 \mathrm{e}$ & 0,075 & $-0,78 \mathrm{de}$ \\
\hline
\end{tabular}

Tabel 6. Pengaruh Genotip terhadap Daya Berkecambah 16 Genotip Calon Tetua Jagung Manis Hibrida Unpad

\begin{tabular}{ccccc}
\hline & \multicolumn{3}{c}{ Daya Berkecambah (\%) } \\
\cline { 2 - 5 } Gen & & & \multicolumn{2}{c}{ Rata-rata } \\
otip & 2 BSP & 4 BSP & $0-2$ & $2-4$ \\
\cline { 3 - 5 } & & & BSP & BSP \\
\hline 547 & $87,5 \mathrm{~b}$ & $60,00 \mathrm{a}$ & $-3,75$ & $-27,5$ \\
578 & $100 \mathrm{a}$ & $73,75 \mathrm{a}$ & 18,75 & $-26,25$ \\
628 & $93,75 \mathrm{a}$ & $75,00 \mathrm{a}$ & $-1,25$ & $-18,75$ \\
666 & $92,50 \mathrm{a}$ & $73,75 \mathrm{a}$ & 10 & $-18,75$ \\
664 & $83,75 \mathrm{~b}$ & $60,00 \mathrm{a}$ & 2,5 & $-23,75$ \\
699 & $93,75 \mathrm{a}$ & $80,00 \mathrm{a}$ & 7,5 & $-13,75$ \\
711 & $96,25 \mathrm{a}$ & $63,75 \mathrm{a}$ & 1,25 & $-32,5$ \\
722 & $81,25 \mathrm{~b}$ & $70,00 \mathrm{a}$ & $-1,25$ & $-11,25$ \\
848 & $81,25 \mathrm{~b}$ & $56,25 \mathrm{a}$ & $-11,25$ & -25 \\
844 & $86,25 \mathrm{~b}$ & $73,75 \mathrm{a}$ & $-6,25$ & $-12,5$ \\
857 & $85,00 \mathrm{~b}$ & $78,75 \mathrm{a}$ & $-6,25$ & $-6,25$ \\
824 & $96,25 \mathrm{a}$ & $66,25 \mathrm{a}$ & 8,75 & -30 \\
849 & $91,25 \mathrm{a}$ & $40,00 \mathrm{a}$ & $-1,25$ & $-51,25$ \\
835 & $100 \mathrm{a}$ & $53,75 \mathrm{a}$ & 1,25 & $-46,25$ \\
837 & $96,25 \mathrm{a}$ & $65,00 \mathrm{a}$ & 13,75 & $-31,25$ \\
858 & $96,25 \mathrm{a}$ & $63,75 \mathrm{a}$ & 3,75 & $-32,5$ \\
\hline & & & &
\end{tabular}

\section{Daya Berkecambah}

Daya berkecambah benih memberikan informasi mengenai kemampuan benih untuk tumbuh normal di lapangan dengan kondisi yang sub optimum (Sutopo, 2004). Standar minimal daya berkecambah menurut Kepmentan No. 355 Tahun 2015 layak dikatakan benih bermutu jika berada diatas atau sama dengan $80 \%$. Berdasarkan data analisis statistik daya berkecambah 16 genotip jagung manis berbeda nyata pada 2 BSP yaitu ada rentang $80-100 \%$, dan tidak berbeda nyata pada 4 BSP dengan rata-rata presentasi daya berkecambah dibawah standar minimal. Daya 
berkecambah pada 4 BSP tidak berbeda nyata menunjukan bahwa besarnya daya berkecambah rata-rata rendah, hampir seluruh genotip dibawah standar minimal kecuali genotip 699 yang masih memiliki daya berkecambah $80 \%$ (Tabel 6).

Daya berkecambah genotip jagung manis dari galur SR pada 2 BSP sangat baik namun penurunannya juga besar pada 4 BSP. Penurunan daya berkecambah benih juga berbanding lurus dengan penyusutan bobot 100 butir, juga nilai DHL yang berhubungan dengan jumlah cadangan makanan pada benih (Tabel 4). Bobot 100 butir pada galur SR cenderung lebih kecil daripada galur $\mathrm{P}$.

\section{KESIMPULAN}

Berdasarkan data setiap parameter pengamatan pada bulan ke 2 dan 4 BSP dan data perubahan kualitas benih setelah penyimpanan dibandingkan dengan kualitas awal penyimpanan, setiap genotip calon tetua yang mengalami perubahan paling sedikit adalah yang paling baik sehingga disimpulkan sebagai berikut:

1. Dari ke 16 genotip jagung manis Unpad terdapat perbedaan nyata pada parameter pengamatan daya hantar listrik, daya berkecambah, bobot 100 butir, dan pada 2 BSP, bobot 100 butir pada 4 BSP.

2. Genotip benih terbaik adalah genotip 578 dengan mutu fisiologis terbaik yang berasal dari galur $\mathrm{P}$ berdasarkan data perubahan genotip.

\section{DAFTAR PUSTAKA}

Azizah, E., A. Setyawan, M. Kadapi, Y. Yuwariah, dan D. Ruswandi. 2017. Identifikasi morfologi dan agronomi jagung hibrida Unpad pada tumpangsari dengan padi hitam di dataran tinggi Arjasari Jawa Barat. J. Kultivasi. 16: 260-264.
Badan Pusat Statistik. 2016. Produksi Tanaman Pangan. https://www.bps.go.id/publication/2016/0 1/04/7249e055c41aaba18ee7e956/produk si-tanaman-pangan-angka-tetap2015.html. Diakses tanggal 5 Mei 2017.

Badan Penelitian dan Pengembangan Pertanian. 2008. Mengenal Jagung Hibrida dan Komposit. Balai Pengkajian Teknologi Pertanian, Yogyakarta.

Direktorat Jenderal Tanaman Pangan. 2016. Petunjuk Teknis Gerakan Pengembangan Jagung Hibrida. Kementrian Pertanian, Jakarta.

Direktorat Jenderal Tanaman Pangan. 2017. Petunjuk Pelaksanaan Kegiatan Budidaya Jagung. Kementrian Pertanian, Jakarta.

Gasperz, V.1995. Metode Perancangan Percobaan untuk Ilmu-Ilmu Pertanian, Teknik dan Biologi.CV. Armico, Jakarta. Justice, Oren L dan Bass, Louis N. 2002. Prinsip dan Praktek Penyimpanan Benih. Jakarta: PT. Raga Grafindo Persada

Kusandriani Y dan Permadi AH. 1996. Pemuliaan tanaman cabai. Di dalam: Duriat

AS, Hadisoeganda AWW, Soetiarso TA, Prabaningrum L, editor. Teknologi Produksi Cabai Merah. Lembang (ID): Balai Penelitian Tanaman Sayuran. Hlm 28-35.

Purwono dan R. Hartono. 2008. Bertanam Jagung Unggul. Jakarta: Penebar Swadaya.

Sadjad, S. 1993. Dari Benih Kepada Benih. Jakarta: PT. Gramedia

Sutopo, Lita. 2004.Teknologi Benih. Jakarta: PT Raja Grafindo Persada

Takdir, A., S. Sunarti, and M.J. Mejaya. 1987. Pembentukan Varietas Jagung Hibrida. http://balitsereal.litbang.pertanian.go.id/w p-content/uploads/2016/11/sepuluh.pdf. Diakses tanggal 5 Juni 2017.

Tatipata, Aurellia., Prapto Yudono., AzizPurwantoro, Woerjono Mangoendidjojo. 2004. Kajian Aspek Fisiologi Dan 
58|Paspalum: Jurnal IImiah Pertanian Vol. 6, No.1, Maret 2018

Biokimia Deteriolasi Beih Kedelai dalam

Penyimpanan. Ilmu Pertanian Vol. 11

No. 2, 2004 : 76-87. 